\title{
Symptomatic arachnoiditis ossificans of the thoracic spine. Case report
}

\author{
Y Toribatake, H Baba, Y Maezawa, S Umeda and K Tomita \\ Department of Orthopaedic Surgery, School of Medicine, Kanazawa University, Takaramachi 13-1, Kanazawa, \\ Ishikawa 920, Japan
}

This report describes a man aged 65 years who developed spastic paraparesis secondary to arachnoiditis ossificans in the thoracic spine. Over 35 years previously, in Southeast Asia, the patient had received repeated lumbar punctures in the treatment of meningitis possibly associated with malarial fever. He had multiple arachnoidal ossifications located at levels from T6 to T9 dorsal to the spinal cord which were well delineated by computed tomography. The lesions were completely extirpated by dorsal route surgery, and the patient had marked neurological improvement after surgery. Histology confirmed that the lesions showed mature bone that formed with an osseous marrow and trabeculae, and the lesions exhibited clusters of arachnoidal cells as well as the proliferation of osteoblasts surrounding the ossified area. Early diagnosis and surgical intervention, however, are mandatory in such cases, if the patient is to attain an acceptable degree of recovery.

Keywords: arachnoiditis ossificans; paraparesis; mesenchymal metaplasia; arachnoidal cells

\section{Introduction}

On the basis of autopsy findings, Knoblich and Olsen ${ }^{1}$ found that as many as $43 \%$ of their 217 specimens had calcification or ossification of the leptomeninges. The presence of such plaques, however, may only rarely be of clinical significance during the bearer's life. Chronically progressive ossification of the arachnoid membrane subsequently leads to such devastating neurological sequelae that it is vital that the sequelae be remedied surgically in a timely manner. The case presented here is illustrative of a patient who probably suffered progressively from the disease, although at a slow degree, after a malarial infection accompanied by meningitis which had been treated with repeated lumbar punctures.

\section{Case report}

The patient, a 65-year-old man had a 4-year history of persistent pain, numbness, and stiffness in the lower extremities. Eventually he was unable to ambulate without the assistance of two crutches 4 years following the onset of symptoms, because of the frequent muscle twitches in his legs. A review of his past medical history revealed nothing remarkable beyond a malarial infection followed by meningitis more than 35 years before when he was stationed in tropical Southeast Asia. Following a bout of malarial fever which continued for about 9 days, he suffered from complications due to severe meningitis. At that time, repeated cerebrospinal fluid studies by lumbar punctures were per-

Correspondence: Hisatoshi Baba MD, Associate Professor, Department of Orthopaedic Surgery, Fukui Medical School, Shimoaizuki 23, Matsuoka, Fukui 910-11, Japan formed. The patient reported that the disease had been cured over a period of approximately 1 month following hospital admission. Unfortunately, no specific details were available concerning the organisms in the cerebrospinal fluid, subarachnoidal haemorrhage, or intrathecal therapy.

Neurological examinations on admission indicated that the patient had a spastic paraparesis, and had hypoaesthesia, predominantly distal, below the T10 segment. Joint position and vibration senses were diminished below the knees. The patellar and Achilles tendon reflexes were bilaterally hyperactive, and there was ankle clonus and plantar extensor reflexes. The Valsalva manoeuver provoked severe radicular pain along the entire left lower extremity. Muscle motor testing of the lower extremities revealed four-fifths of normal strength in the rectus femoris, the anterior tibial, the biceps femoris, and the gastrocnemius muscles. Bladder and bowel functions were both disturbed, as was evidenced by residual urine, incontinence, and impaired sensation of defaecation. The upper extremities were normal neurologically. Blood chemistry showed no abnormalities in calcium/phosphate concentrations or related metabolism. A diagnosis of neurosyphilis was excluded by blood tests and by a negative cerebrospinal fluid study, except for slightly elevated protein levels of $58 \mathrm{mg} 100 \mathrm{ml}^{-1}$ evidenced in Nissl-Esbach testing.

Plain radiography and lateral tomography showed multiple ossifications located anterior to the laminae at levels from T6 to T9. A myelogram demonstrated that the spinal cord was compressed posteriorly and irregularly by these ossifications between T6 and T10 (Figure 1). Unenhanced computed tomography clearly demonstrated an ossified mass with no contiguity to the laminae and facet joints, and with a crescent lesion located independent of the surrounding tissues within the spinal canal (Figure 2). A possible diagnosis of arachnoiditis ossificans was made, but the use of magnetic resonance imaging for further examination of the spinal cord was not available. 


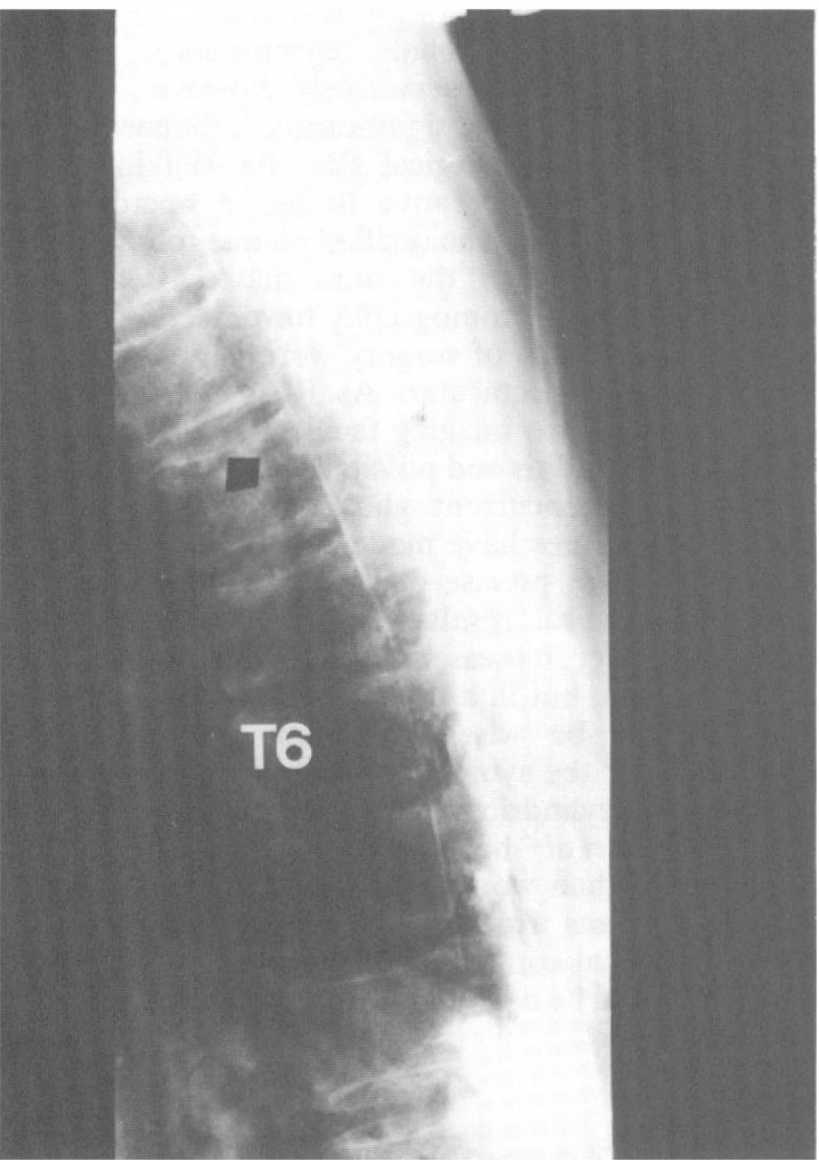

Figure 1 A myelogram demonstrating irregular compression of the spinal cord posteriorly at levels from $\mathrm{T} 6$ to $\mathrm{T} 9$

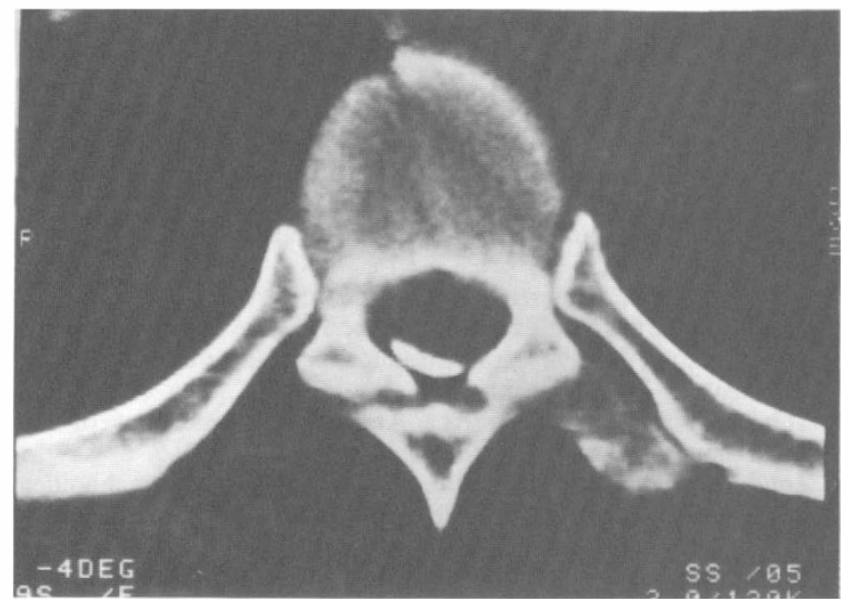

Figure 2 Unenhanced computed tomography showing an ossified mass located within the spinal canal at the T7 level, and without continuity to the laminae and facet joints

A total laminectomy from $\mathrm{T} 4$ to $\mathrm{T} 9$ was performed. At surgery, the laminae were found not to have adhered to the dural sac and no ossification or calcification of the ligamentum flavum was evident. At T6 and T7, part of the thecal sac coloured yellowish white was noted to contain hard elements, and beyond this level dural pulsation in conjunction with cardiac rhythms was absent. The firm and dense dural sac was then explored from T6 to T8, and an irregular $45 \mathrm{~mm}$-long segment of bony tissue adherent to the theca was extirpated with a microsurgical technique. The lesion itself, however, had compressed the spinal cord severely but did not appear to be adherent to the pial membrane. The arachnoid surrounding the bony plaque was semitransparent, suggesting chronic inflammation. Further exploration was followed by resection of the small osseous fragments at T8 and T9. The dura was closed in a watertight manner.

Histology confirmed that the resected specimens were mature bone with normal fatty marrow and trabecular formations within them (Figure 3). Arachnoidal cell clusters and a marked proliferation of osteoblasts were evident between the bony trabeculae (Figure 4), but there were no calcium crystal deposits or proliferation of inflammatory cells such as lymphocytes and neutrophils.

The postoperative course was uneventful, and the patient

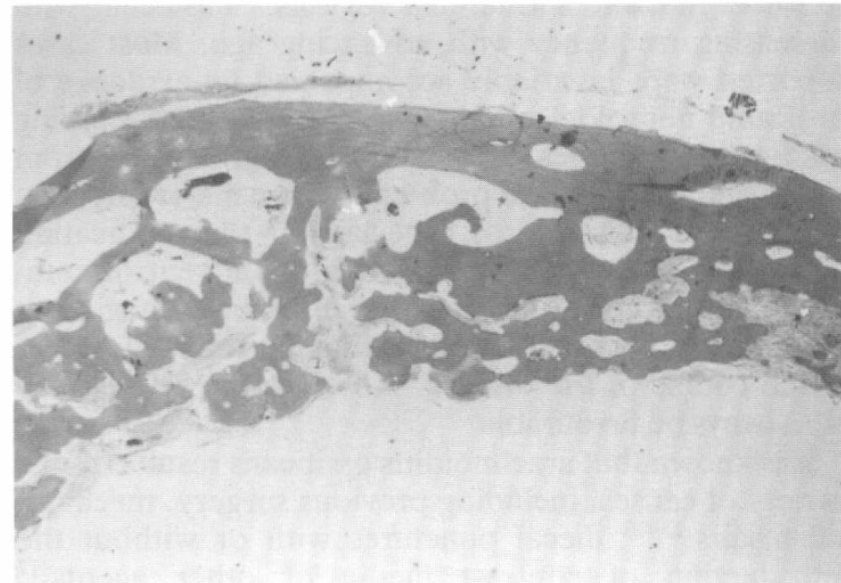

Figure 3 The resected specimen showing mature bone with fatty marrow formation and osseous trabecular patterns $(\times 4$ objective $)$

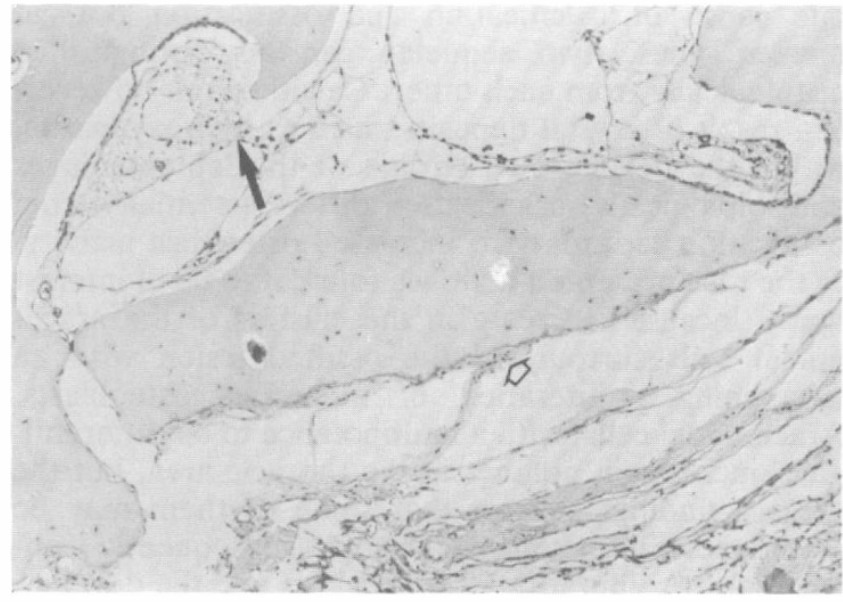

Figure 4 A cluster of arachnoid cells (arrow) and proliferation of the osteoblast (open arrow) are observed surrounding the bony trabeculae (Haematoxilin and Eosin stain $\times 100$ objective). 
was able to walk unaided 7 months after surgery with a minimal persistence of bilateral hypoaesthesia in the feet. The bladder was functioning normally 10 months postoperatively. In a follow-up examination 6 years later, the patient was found to be well and showed no signs or symptoms of recurrence of neurological abnormalities.

\section{Discussion}

Small ossifications and calcifications of the spine, including the arachnoid, are not uncommon findings in postmortem examinations. ${ }^{2}$ The documented incidence of ossified plaques with clinical presentation, however, is not high and only 55 case reports are currently available for review. Based on a recent review made by Kitagawa et al, ${ }^{3}$ the thoracic spine is involved in $66 \%$ of all patients and the lumbar spine in $24 \%$, with only two cases having lesions located from the lower cervical to the thoracic spine. These osseous masses are usually found in the dorsal arachnoid membrane of the middle to lower thoracic and lumbar regions ${ }^{4}$ and occur with increasing frequency with advancing age. Most cases reported were invariably accompanied by evidence of profound neurological deficits. ${ }^{5-12}$ Patients developing ossification plaques may suffer progressively from significant neurological problems with a major effect on the related spinal cord, especially if the ossification occurs in the thoracic spine. With the advent of computed tomography and magnetic resonance imaging, it has become possible to treat patients surgically earlier in the course of the disease. However the results may not always be favourable.

It is known that arachnoiditis ossificans results from a variety of causes, including previous surgery, mechanical insults, ${ }^{13-16}$ thecal punctures with or without the introduction of contrast media or other agents, ${ }^{17}$ infection, ${ }^{18}$ vascular anomaly, ${ }^{19}$ and subarachnoid haemorrhage.$^{20,21}$ The possible mechanism behind the ossification of the leptomeninges, especially the arachnoid, is an issue which continues to draw interest. With respect to its pathogenesis, Herren ${ }^{22}$ reported that hyperplastic degeneration of the arachnoidal cells is one cause of calcification and ossification but, at present, these two sequelae can be distinguished histologically from each other. Calcification, however, is a result of crystal deposits, such as hydroxyapatite, within the degenerated stroma of the leptomeninges and, biologically, calcification differs essentially from ossification secondary to increased osteoblast activity. In the case presented here, we found it to be of interest that a localised increase in the clusters of the arachnoidal cells surrounded the ossified lesion with an intervening proliferation of numerous osteoblasts. Arachnoidal cells, with a multipotence to be differentiated, increase in number in the thoracic area, but the present findings suggest that some of them may be associated with metaplastic changes subsequently leading to the proliferation of osteoblasts and the development of ossification.

Patients with severe symptoms related to arachnoiditis ossificans or even showing impending paresis should be considered candidates for surgical resection, espe- cially if their clinical condition is found to be progressively deteriorating. Small asymptomatic ossicles should be observed conservatively, however, because the surgery itself may significantly enhance further arachnoiditis at the surgical site. As Wilkinson has suggested, ${ }^{23}$ it is imperative to use a microsurgical technique in resecting the ossified plaque followed by a water-tight closure of the dura mater. Before the advent of computed tomography for detecting osseous lesions, ${ }^{24}$ the results of surgery were varied and were often less than spectacular. As Ross has reported, ${ }^{25}$ magnetic resonance imaging facilitates the early diagnosis of arachnoiditis and possible changes in the spinal cord such as concurrent gliosis and syringomyelia. Imaging techniques have made it possible to establish earlier and more precise diagnoses that ensure more favourable surgical results than ever before. In the course of surgery, it is essential completely to excise the ossified lesions, but in a patient with multiple ossifications, it may be wiser to resect only the lesion responsible for the symptoms. Moreover patients with columnar and cylindrical lesions within the spinal cord, such as Jaspan $e a^{26}$ have shown, appear to benefit less from surgery than would be hoped. A case of arachnoiditis ossificans which has developed only peripherally to the spinal cord, such as in the current case, for example, would be easier to address surgically.

\section{References}

1 Knoblich R, Olsen BS. Calcified and ossified plaques of the spinal arachnoid membranes. J Neurosurg 1979; 25: 275-279.

2 Bullough PG, Boachie-Adjei O. Deposition disease affecting the spine. In: Bullough PG, Boachie-Adjei O (eds). Atlas of Spinal Diseases. JB Lippincott: Philadelphia 1988; pp 68-75.

3 Kitagawa H. Multiple spinal ossified arachnoiditis. Spine 1990; 15: $1236-1238$

4 Kaufman AB, Dunsmore RH. Clinicopathological considerations in spinal meningeal calcification and ossification. Neurology $1971 ; 21$ : 1243-1248.

5 Carbone F, Hasaerts R, Cordier J. Ossification diffuse de l'arachnoide spinale. Acta Neurol Belg 1954; 54: 183-191.

6 Slager UT. Arachnoiditis ossificans: report of a case and a review of the subject. Arch Pathol 1960; 70: 322-327.

7 Romerance A. Spinal arachnoiditis ossificans. J Pathol Bacterial 1964; 87: 421-423.

8 Soloviev VN. Changes in the spinal cord in the so-called spinal ossificating arachnoiditis. Arch Pathol 1973; 35: 48-54.

9 Varughese G. Lumbosacral intradural periradicular ossification. J Neurosurg 1978; 49: 132-137.

10 Tetsworth KD, Ferguson RL. Arachnoiditis ossificans of the cauda equina: a case report. Spine 1986; 11: 765-766.

11 Zanda L. Ueber die Entwichlung der Osteome der Arachnoidea spinales. Beitr Pathol Anat 1889; 5: 393-400.

12 O'Rouke, Simeone FA. Subacute onset of thoracic myelopathy secondary to compressive posterior osseous anomaly. Case report. Spine 1991; 16: 990-991.

13 Puusep L. Surgical intervention in four cases of myelitis compression caused by osseous deposits in the arachnoidea of the spinal cord. J Nerv Ment Dis 1931; 73: 1-19.

14 Nainkin L. Arachnoiditis ossificans. Report of a case. Spine 1978; 3: 83-86.

15 Dennis MD, Altschuler E, Glenn W, Wiltse LL. Arachnoiditis ossificans: a case report diagnosed with computerized axial tomography. Spine $1983 ; 8$ : 115-117.

16 Lynch C, Moraes GP. Spinal arachnoiditis ossificans. Case report. Neurosurgery $1983 ; 12$ : 312-314.

17 Wise BL, Smith M. Spinal arachnoiditis ossificans. Arch Neurol 
1965; 13: 391-400.

18 Gulati DR, Bhandari YS, Markand ON. Spinal arachnoiditis ossificans. Neurol India 1965; 13: 196-198.

19 Gatzke LO, Dodge HW, Docherty MB. Arachnoiditis ossificans: report of two cases. Proc Mayo Clin 1957; 32: 698-704.

20 McCulloch GAJ. Arachnoid calcification producing spinal cord compression. J Neurol Neurosurg Psychiatry 1975; 38: 1059-1062.

21 Whittle IR, Dorsch NW, Segelov JN. Symptomatic arachnoiditis ossificans. Report of two cases. Acta Neurochir 1982; 65: 207-216.

22 Herren RY. Occurrence and distribution of calcified plaques in the spinal arachnoid in man. Arch Neuro Psychiatry 1936; 41: $1180-1186$.

23 Wilkinson HA. Alternative therapies for the failed back syndrome. In: Frymoyer JW (ed). The Adult Spine: Principles and Practice. Laven Press: New York, 1991, pp 2069-2091.

24 Barthelemy CR. Case report: arachnoiditis ossificans. J Comput Assist Tomogr 1982; 6: 809-811.

25 Ross JS. Inflammatory disease: arachnoiditis. In: Modic MT, Masaryk TJ, Ross JS, (eds). Magnetic Resonance Imaging of the Spine. Year Book Medical: Chicago, 1989, pp 167-172.

26 Jaspan T, Preston BJ, Mulholland, Webb JK. The CT appearance of arachnoiditis ossificans. Spine 1990; 15: 148-151. 